\title{
THE INFLUENCE OF BUD LOADS ON MECHANICAL AND CHEMICAL CONTENT OF BUNCHES OF KATTAKURGAN GRAPES VARIETY
}

\author{
Pulatjon Ergashevich Egamberdiev \\ Doctoral Candidate (PhD), Fruit Growing and Viticulture Department, Tashkent State Agrarian \\ University, Tashkent, Uzbekistan
}

Azim Nematovich Malikov

Assistant of the Department of Oenology,

Tashkent Chemical Technological Institute, Tashkent, Uzbekistan

Article DOI: https://doi.org/10.36713/epra3897

\begin{abstract}
In this article the influence of bud load of Kattakurgan variety of grape for table use has been studied on its mechanical and chemical content. According to the results of investigations it was determined that when 160-200 pieces of buds were remained per vine plant, the mass of grapes bunch constituted 14,8 g more than control variant and was differentiated from other variants with its larger grape bunches, when 80-120 pieces of buds were left on vine plants by their mechanical content the sugar content was higher and acidity was low accordingly.
\end{abstract}

KEYWORDS: bud, grape for table use, load, mechanical content, bunch of grapes, pulp, skin, seed, juice.

\section{INTRODUCTION}

Mechanical content of grape bunch is one of main features of vine. Mainly in the varieties for table use the view of bunch, full maturation, the size of bunches are basic factors that allow this variety to be a main raw material for the production of not only fresh and dried products, but also canned products. The amount and quality of yield depend on sustainability and growth strength of the vine plant. The more growth strength increases, the more yield is obtained accordingly, and quality increases, the more grape bunches and cluster size enlarge, the number of shoots of vine plant and their growth strength rise too $[1,4,6]$.

The influence of growth strength and different load rates of vine on productivity has been studied thoroughly by Guseynov Sh.I and other scientists and as they stated, the increase in the load of vine plants with shoots, i.e. to $63 \%$, caused $86 \%$ rise in the amount of grape bunches on vine plants. But the yield increased less, average mass of grape bunch decreased by $17 \%$. More than 50 pieces of shoots load on vine plants allowed to increase the number of grape bunches. But it was defined that the mass of grape bunches decreased to $45-50 \%$. This shows that overload on vine plants can influence adversely $[2,5]$.

\section{MATERIALS AND METHODS}

The experiments of the research were conducted in "Fruit growing and viticulture" department of Tashkent state agrarian university and on the farm "Karima muruvvat Agro" in Tashkent district of Tashkent region, on 9 years old vine plants of "Kattakurgan" variety of grape for table use. Selection of performed experiments, their arrangements were done by common methods, statistical analysis of data was carried out by the method of N.I. Ryabova and I.L. Vytkovisky [3].

Having been sown by thickening according to Voish method in the experiment, the vine plants were loaded with 80-120 pieces of buds (control), 120-160 pieces, $160-200$ pieces, $200-240$ and $240-280$ pieces of buds in five variants. Each variant was performed in 3 repetitions. Kattakurgan grape variety is functional variety with female flowers and that's why in order to pollinate it the varieties Pushty Toify, Rizamat, Ok khusayniy and Kora kishmish were planted around it.

\section{RESULTS AND DISCUSSION}

The weight of bunch of grape for table use, its bunches, pulp, skin, juice and seeds were weighed with analytic scales and calculated in percentage. Weighing 
of the bunch of grapes was done with ruler. Sugar content of grape juice was tested with aerometer, while acidity was checked by titration of sodium sulfate. As the results obtained have been presented in table-1, in control variant of Kattakurgan variety with 80-120 pieces of grape bunches, the weight of bunch constituted $440,5 \mathrm{~g}$, the size was $28 \times 20 \mathrm{~cm}$, bunch 5,4 $\%$, skin $-0,4 \%$, pulp and juice $-87,5 \%$ and seed $-6,7$ $\%$. With 120-160 pieces of bud loads the weight of

bunch of grapes constituted $6,7 \mathrm{~g}$ less, size $0,2 \mathrm{~cm}$ more, bunch $0,1 \%$ less, skin $0,1 \%$ more, pulp and juice production $0,2 \%$ less and seed $0,2 \%$ less comparing to control variant. When 160-200 pieces of buds were left on vine plants, the mass of grape bunch was $14,8 \mathrm{~g}$ more, size $2,3 \mathrm{~cm}$ longer, bunch $0,5 \%$ less, skin $0,1 \%$ more, pulp and juice production $0,1 \%$ more and seed $0,3 \%$ more than control variant.

Table 1

Mechanical content of grape bunch of Katta kurgan variety (in 2018-2019)

\begin{tabular}{|c|c|c|c|c|c|c|}
\hline \multirow[b]{2}{*}{ Variants } & \multicolumn{2}{|c|}{ Grape bunch } & \multicolumn{4}{|c|}{ Grape bunch mass content, \% } \\
\hline & mass, $\mathrm{g}$ & size, $\mathrm{cm}$ & $\begin{array}{l}\text { pulp and } \\
\text { juice }\end{array}$ & bunch & Skin & seed \\
\hline $80-120$ pcs of buds (control) & 440,5 & $28 \times 23$ & 87,5 & 5,4 & 0,4 & 6,7 \\
\hline $120-160$ pcs of buds & 147,2 & $28 \times 25$ & 87,3 & 5,3 & 0,5 & 6,9 \\
\hline $160-200$ pcs of buds & 455,3 & $30,5 \times 26$ & 87,6 & 4,9 & 0,5 & 7,0 \\
\hline $200-240$ pcs of buds & 437,9 & $28,4 \times 23$ & 87,1 & 5,1 & 0,4 & 7,4 \\
\hline $240-280$ pcs of buds & 425,4 & $26,8 \times 22$ & 87,2 & 5,0 & 0,5 & 7,4 \\
\hline
\end{tabular}

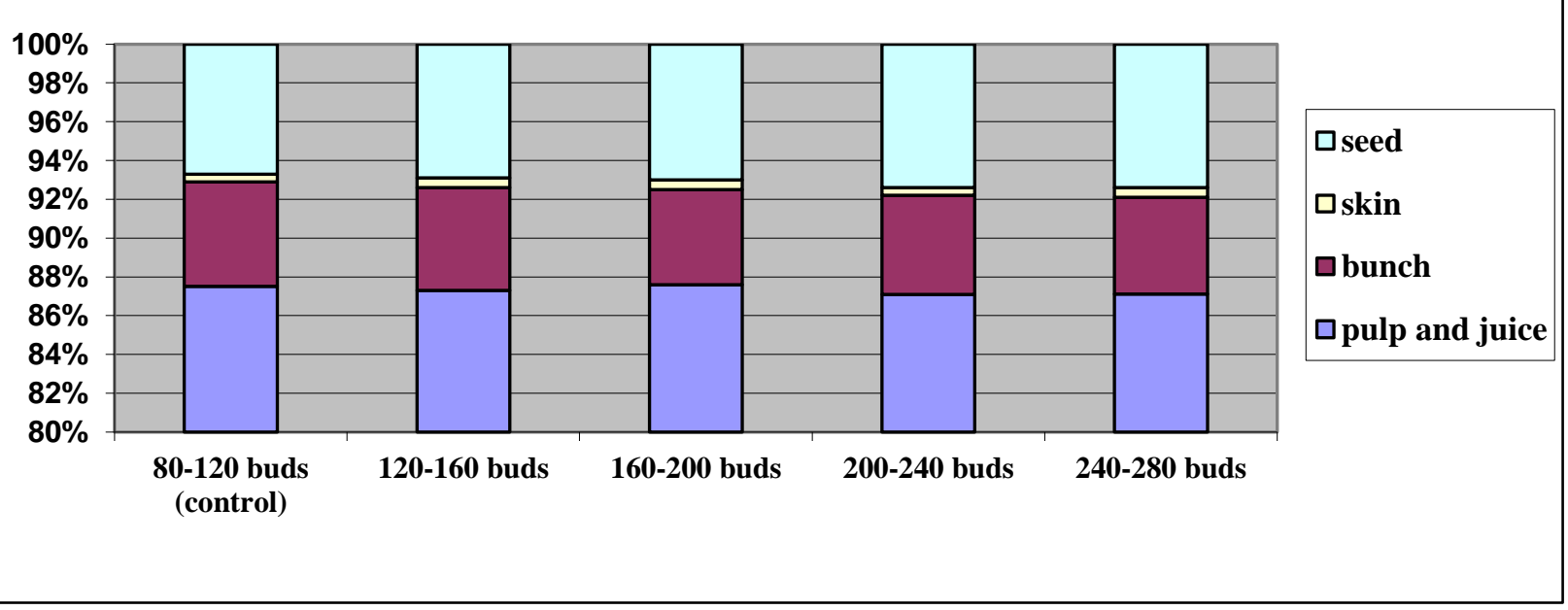

Figure 1. Mechanical content of grape bunch of Katta kurgan variety

With 200-240 pieces of bud loads the mass of grape bunch made 2,6 g less, size was equal, bunch 0,3 $\%$ less, skin was equal, pup and juice yield $0,4 \%$ less, and seed yield was $0,7 \%$ more comparing to control variant. It was also determined that with $240-280$ pieces of bud load the weight of grape bunch constituted $15,1 \mathrm{~g}$ less, size $1,2 \times 1,0 \mathrm{~cm}$ less, bunch $0,4 \%$ less, skin $0,1 \%$ more, pulp and juice yield $0,3 \%$ less and seed yield $0,7 \%$ more than in control variant.

The influence of bud load on chemical content of Kattakurgan cultivar of vine has been determined in the result of conducted investigation (table-2). When 80120 pieces of buds were kept in Kattakurgan vine variety (control), sugar content was noted to be $23,1 \%$ and acidity 3,2 g/l. With $120-160$ pieces of buds, the indication of sugar was less by $0,2 \%$ and acidity was more by $0,1 \%$. With $160-200$ pieces of buds on vine plant, sugar content of grape constituted $0,1 \%$ less and acidity $0,2 \mathrm{~g} / 1$ more than others. 
Table 2

Chemical content of Katta kurgan variety of crunchy vine

\begin{tabular}{|l|c|c|}
\hline \multicolumn{1}{|c|}{ Variants } & Sugar amount, \% & Acidity, $\mathbf{g} / \mathbf{l}$ \\
\hline $80-120$ pcs of buds (control) & 23,1 & 3,2 \\
\hline $120-160$ pcs of buds & 22,9 & 3,3 \\
\hline $160-200$ pcs of buds & 23,0 & 3,4 \\
\hline $200-240$ pcs of buds & 22,7 & 3,4 \\
\hline $240-280$ pcs of buds & 22,6 & 3,5 \\
\hline
\end{tabular}

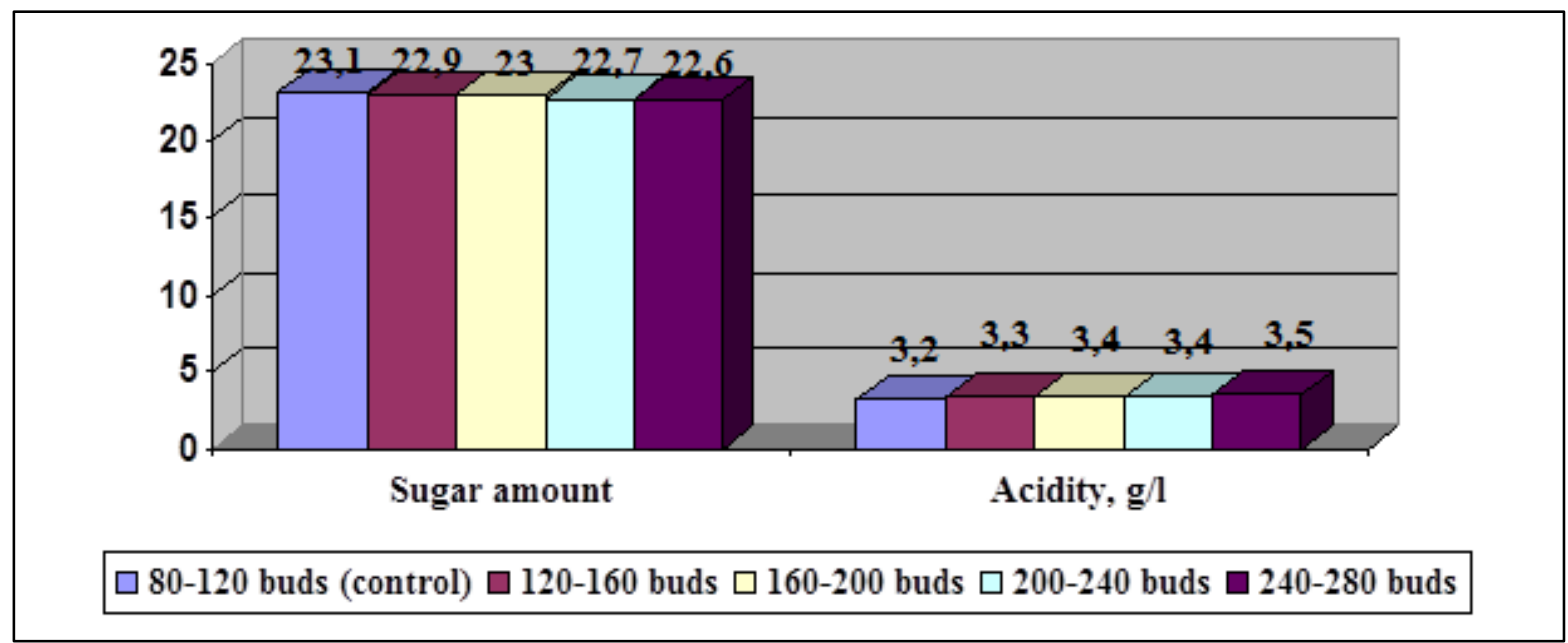

Figure 2. Chemical content of juice of Kattakurgan grape variety

With 200-240 pieces of buds processed vine grape contained 0,4 \% less sugar and 0,2 g/l more acidity. While with 240-280 pieces of bud load, its sugar content was noted to be $0,5 \%$ less and $0,3 \mathrm{~g} / 1$ more acidity.

\section{CONCLUSION}

When bud loads are left on vine plants more or less than the norm, it can cause yield decrease and effect adversely to chemical content of grape juice.

When vine plant was planted with thick bud load of 160-200 pieces, it was observed that the weight of bunch of grapes and their mechanical content were higher than in other variants. With $80-120$ pieces of bud load on vine plants by chemical content, sugar content was found to be high while acidity was in low indication.

\section{REFERENCES}

1. Arutinyan A.S. (1983). Vinery fertilizers. Moscow: Kolos, pp. 43-45.

2. Guseynov Sh.N. (1999). Perspective methods for the cultivation of vine of industrial and super-intensive type in Russian federation. Materials from scientific-practical conference on "Horticulture and viticulture of XXI century” Krasnodar. pp.18-21.
3. Ryabova N.I, Vyktovisky V.L. (1998). The study of grape varieties (Methodological guide), Leningrad, pp. 22-28.

4. Temurov Sh. (2002). Viticulture - Tashkent, “” National encyclopedia of Uzbekistan”, state publishing house, pp. 174-175.

5. The factors of producing high yield of grape in Fergana region, Fergana, 2009. 12 p.

6. Zhavakyans Yu.M., Gorbach V.I. (2001). Grapes of Uzbekistan. "Sharq". pp. 42-44. 